\title{
A1 Düzeyindeki Yabancı Dil Olarak Türkçe Öğretimi Ders Kitaplarında Yer Alan Konuşma Etkinliklerinin Avrupa Dil Gelişim Dosyası Yeterlilikleri Bağlamında Değerlendirilmesi"
}

\author{
Evaluation of the Speaking Activities in the Teaching Of Turkish as a Foreign Language Course \\ Book at Al Level in the Context of Common European Language Portfolio
}

\author{
Muhammed Eyyüp Sallabaş ${ }^{* *}$ - Hatice Sağlık**
}

\begin{abstract}
It is certain that important steps have been taken in teaching Turkish as a foreign language with modern techniques and methods. However, problems in terms of teaching materials continue, and textbooks remain the most important material in this field. Many publications are used in teaching Turkish as a foreign language in Turkey. However, the rates of language use, intermediary language use, measurement and evaluation criteria, number of activities and teaching strategies of these publications differ. Various qualification definitions have been introduced by the Common Europan Framework of References for Languages (CEFR) and the European Language Portfolio (ELP), which is accepted by our country for the speaking skill activities in Turkish teaching textbooks, which is the most effective course teaching material for teaching Turkish as a foreign language. Accordingly, it was aimed to determine the distribution of speaking skill activities in the ELP proficiency definitions in the sets used in teaching Turkish as a foreign language at the elemantary level A1. The case study is carried out in the research, which is one of the qualitative research patterns, document analysis is used as one of the techniques of data obtaining and content analysis is used in the analysis of the data. Within the scope of the research, four sets commonly used in teaching Turkish as a foreign language were examined. According to the results of the research, it was determined that the speaking activities in the textbooks are in favor of mutual speech in terms of percentage. In addition, when the qualifications were examined, it was seen that the levels of placing the qualifications of the books were very different from each other, some qualification definitions were not given at all and there was no compatibility between the books.
\end{abstract}

Structured Abstract: The processes of learning and using mother tongue and foreign languages, and therefore speaking, differ from each other. Hammerly (cited in 1991: 148-149 Colak, 2018: 10) mentions that in the foreign language, the social and cultural environment in which the language learning process takes

\footnotetext{
* Bu çalışma ikinci yazarın "Türkçenin Yabancı Dil Olarak Öğretiminde Kullanılan Ders Kitaplarında Yer Alan Konuşma Becerisi Etkinliklerinin Avrupa Dil Gelişim Dosyası Doğrultusunda Değerlendirilmesi” isimli yüksek lisans tezinden üretilmiştir.

*** Doç. Dr., Yıldız Teknik Üniversitesi Eğitim Fakültesi Türkçe ve Sosyal Bilimler Eğitimi Bölümü Assoc. Prof. Dr. Yildiz Technical University Faculty of Education Department of Turkish and Social Sciences ORCID 0000-0003-4346-4385

sallabas@yildiz.edu.tr

*** YL Öğrencisi, Yıldız Teknik Üniversitesi Sosyal Bilimler Enstitüsü

Graduate Student Yıldız Technical University Graduate School of Social Sciences

ORCID 0000-0002-3257-264X

haasyasaglik@gmail.com

Cite as/ Atıf: Sallabaş, M. E. \& Sağlık, H. (2020). A1 düzeyindeki yabancı dil olarak Türkçe öğretimi ders kitaplarında yer alan konuşma etkinliklerinin Avrupa dil gelişim dosyası yeterlilikleri bağlamında değerlendirilmesi. Turkish Studies - Education, 15(3), 2033-2046. https://dx.doi.org/10.29228/TurkishStudies.42977

Received/Geliş: 20 April/Nisan 2020

Accepted/Kabul: 21 June/Haziran 2020

Checked by plagiarism software

Copyright (C) INTAC LTD, Turkey 
place and the environment in the acquisition of the second language have quite different characteristics. In the acquisition of the second language, the rules of the language, use cases, social situations, etc. It can be said that the target language experiences and activities in the foreign language are carried out in a classroom environment and compressed to a certain time, as opposed to a process that progresses with a pattern intertwined with all aspects of the language. Therefore, the ways in which a student learning Turkish outside the countries spoken as a mother tongue develop their speaking skill and the level of development of speaking skill in countries spoken as their mother tongue differ. This also affects the quality of the material used and the teaching process.

It is seen that the concept that forms the basis of the studies conducted within the framework of the of the Communicator Language is communicative acquisition (Fidan, 2016: 133). Hymes (cited in 1972 Çetin, 2017: 184) stated that knowing the language in the appropriate context is creating appropriate uses and knowing who, when, what, and how to say "communicative acqusition". Canale and Swain (1980: 29-30) discuss the communicative gain under three sub-titles as grammatical, sociolinguistic and strategic acqusitions. Canale (1983: 9) then adds his distext to three dimensions and evaluates the communicative acquisition in four dimensions. Acqusition. Bayraktar (2014: 116) interprets this concept in general, as well as the abstract rules necessary to interact with a community using a common language, having the skills necessary for their local use in accordance with social norms. In the teaching of Turkish as a foreign language, speaking skill has an important place in gaining communicative skill. As a matter of fact, speaking is an important process in gaining communicative skill since it requires an interactive process and generally requires interaction with speakers of the language learned as the mother tongue.

The processes for improving the speaking skill in teaching Turkish as a foreign language are generally shaped within the framework of the activities in the sets. These activities should be prepared to achieve communicative acquisition within the framework of Common Europan Framework of Reference for Languages (CEFR). As a matter of fact, the studies of İşisağ (2008) and Taşköprü (2017) show that the verbal communication skills curriculum prepared according to the European Language Portfolio (ELP) approach in speaking skill gives significant positive results compared to traditional understanding.

ELP covered different dimensions of speaking skill (independent speech and conversation) and included descriptors of each dimension. In this study, it was aimed to determine the status of the distribution of speech skill activities in ELP proficiency definitions in the sets used in teaching Turkish as a foreign language at the elemantary level A1. Accordingly, answers to the following questions have been sought.

1. What is the distribution of speaking skill activities in the textbooks used in the teaching of Turkish as a foreign language at A1 level according to the dimensions of the speaking skill (mutual speech and verbal expression) within the context of the ELP?

2. What is the distribution of the speaking skill activities in the textbooks used in the teaching of Turkish as a foreign language at A1 level to the ELP proficiency definitions?

Depending on the research purpose, a case study was used, which is one of the qualitative research methods. Case study, aiming to examine a current event or situation in depth; is a research approach in which multiple research tools are used and accordingly the situation or the factors depending on the situation can be themed (Yin, 2014; Creswell, 2016). In the study, situations related to speaking skills in the Istanbul Turkish for foreigners text and workbooks, Yedi Iklim Turkish text and workbooks, Yeni Hitit Turkish text book, Gazi Turkish for foreigners text and workbooks of A1 level were determined.

Based on the findings obtained in the study, it was determined that there was no balanced distribution in the textbooks in terms of the dimensions of speaking skill (mutual speech and verbal expression). It is thought that the ratio of conversation activities in all textbooks is higher than the verbal expression activities in terms of A1 level being an exploration level for learners of language, the use of language at this level for personal purposes basically, and the most basic level where the learner interacts in the target language with simple interaction. In addition, the competencies included in ELP show a similar distribution. In ELP, there are 11 mutual speaking in the conversation dimension, while there are 3 competencies in the verbal expression dimension. While the proportions of the Istanbul and Gazi set are closer to each other in terms of the numerical distribution of the activities according to the dimensions of the speech, there is a serious difference in favor of mutual speech especially in the Yedi Iklim and Yeni Hitit sets. 
It is determined that at least one proficiency is not included in all textbooks in the distribution data of the activities in the textbooks to the ELP proficiency criteria. KKA1-10 (I can apologize and accept the apologies) is not included in any set. Considering that individuals will need to apologize even in very simple situations in the social life, this situation is considered as a deficiency in sets. However, in the Istanbul set, there is no activity related to the definition of 3 proficiency in speaking skill, while in the Yedi Iklim and Yeni Hitit sets this number is 2 and in the Gazi set it is 1 . This shows that book makers ignore ELP.

In the research, it was determined that some of the activities in the textbooks did not comply with the ELP qualification definitions. 10 of the 61 speaking skills activities in the A1 textbook in Gazi Turkish for foreigners, and 1 of the 35 activities in the Yeni Hitit textbook do not match the ELP qualification definitions. This situation shows that the textbook authors did not take enough attention to the frame text during the writing of the textbook. Considering that foreign language education is carried out according to CEFR in many countries, such differences in proficiency level will cause confusion in terms of language exams and certification. In this respect, while preparing textbooks, common suggestion levels and competencies should be taken into consideration, and activities related to oral expression and conversation should be designed to reflect the targeted quality in the best way possible.

Keywords: Turkish Education, Teaching Turkish to Foreigners, Europan Language Portfolio, Speaking skill, Coursebook

Öz: Türkçenin yabancı dil olarak modern teknik ve yöntemlerle öğretiminde önemli aşamalar kaydedildiği muhakkaktır. Ancak ders öğretim materyali anlamında sorunlar süregelmekte olup ders kitapları eğitim sürecinde en önemli materyal olma özelliğini korumaktadır. Türkiye'de Türkçenin yabancı dil olarak öğretiminde pek çok yayın kullanılmaktadır. Ancak bu yayınların dil becerilerine yer verme oranları, aracı dil kullanma durumları, ölçme ve değerlendirme kriterleri, etkinlik sayıları ve öğretim stratejileri birbirinden farklılık göstermektedir. Türkçenin yabancı dil olarak öğretiminde en etkili ders öğretim materyali olan yabancılara Türkçe öğretim ders kitaplarında yer alan konuşma becerisi etkinlikleri için ülkemizce de kabul edilen Avrupa Ortak Başvuru Metni (AOBM) ve uygulaması niteliğindeki Avrupa Dil Gelişim Dosyası (ADGD) tarafından çeşitli yeterlilik tanımları getirilmiştir. Bu doğrultuda araştırmada, temel düzey A1 seviyesinde Türkçenin yabancı dil olarak öğretiminde kullanılan setlerde yer alan konuşma becerisi etkinliklerinin Avrupa Dil Gelişim Dosyası yeterlilik tanımlarına dağılımını belirlemek amaçlanmış̧ır. Nitel araştırma desenlerinden durum çalışması deseninde gerçekleştirilen araştırmada veri toplama tekniklerinden doküman incelemesi kullanılırken verilerin analizinde içerik analizinden yararlanılmıştır. Araştırma kapsamında Türkçenin yabancı dil olarak öğretiminde yaygın olarak kullanılan dört set incelenmiştir. Araştırma sonuçlarına göre ders kitaplarında yer alan konuşma etkinliklerinin oran bakımından karşıllkklı konuşma lehine olduğu belirlenmiştir. Ayrıca yeterlilikler incelendiğinde kitapların yeterliliklere yer verme düzeylerinin birbirlerinden çok farklı olduğu, bazı yeterlilik tanımlarına hiç yer verilmediği ve kitaplar arasında bir uyumun olmadığ görülmüştür.

Anahtar Kelimeler: Türkçe Eğitimi, Yabancı Dil Olarak Türkçe Öğretimi, Avrupa Dil Gelişim Dosyası, Konuşma Becerisi, Ders Kitabı

\section{Giriş}

Türkçenin yabancı dil olarak modern teknik ve yöntemlerle öğretiminde önemli aşamalar kaydedildiği muhakkaktır. Ancak ders öğretim materyali anlamında sorunlar süregelmekte olup ders kitapları eğitim sürecinde en önemli materyal olma özelliğini korumaktır (Özbay, 2003; İşeri, 2007; Karakoç Öztürk, 2016). Öte yandan dört dil becerisinden biri olan konuşma becerisinin kazandırılması, yabancı dil öğretiminde iletişim için nihai hedef kabul edilebilir (Tüm,2014; Kurudayığlu ve Sapmaz,2016). Yazma becerisi ile birlikte anlatma etkinliğini oluşturan konuşma becerisi, en etkili iletişim aracıdır.

Eğitim süreçlerinde dikkate alınması gereken pek çok konu vardır. Yetkin bir öğretmen, etkili bir program, fiziksel imkânlar, ölçme ve değerlendirme, ders kitapları gibi unsurlar bu süreçte önemli yer tutmaktadır. Özellikle ders kitapları, konuları planlı bir şekilde öğrencilere sundukları 
için hem öğretmenlerin hem de öğrencilerin yararlandıkları ilk kaynak durumundadır (Demirel,1999; Özbay,2003; İşeri 2007) Bu bakımından ders kitaplarının amaca uygun olarak hazırlanması çok önemlidir.

Türkçenin yabancı dil olarak öğretiminde en etkili ders öğretim materyali olan yabancılara Türkçe öğretim ders kitaplarında yer alan konuşma becerisi etkinlikleri, ülkemizce de kabul edilen Avrupa Ortak Başvuru Metni (AOBM) ve uygulaması niteliğindeki Avrupa Dil Gelişim Dosyası (ADGD) tarafindan önerildiği şekilde eylem odaklı ve iletişimsel yeti becerilerini kazandıracak şekilde yer almalıdır. Bu bakımdan ilgili metinlerde dil becerileri ile alakalı çeşitli yeterlilik düzeyleri önerilmektedir. Türkçenin yabancı dil olarak öğretiminde genel olarak kabul gören ve yaygın kullanıma sahip bir programın olmadığı da göz önüne alındığında AOBM ve ADGD’nin rehberliği daha da önemli hâle gelmektedir.

\section{Yabancı Dil Olarak Türkçe Öğretiminde Konuşma Becerisi}

İnsanın birtakım zihinsel ve fiziksel özelliklerini anlık olarak kullanıma sokarak bilgi, görüş, inanç, hayal ve düşüncelerini karşısındakilere sözlü olarak aktarması konuşma olarak ifade edilebilir. Dilin anlatım ve üretim boyutlarından birini oluşturan konuşma, insanın dünyada varlığıyla birlikte kullandığ 1 doğal bir dil yeteneği olarak kabul edilebilir. Konuşma becerisi Aksan'a göre (2007:11), insanı insan yapan niteliklerin başında gelir ve onun duygularını, düşüncelerini, isteklerini bütün incelikleriyle açığa vurmasına, yaşamını sürdürebilmesine imkân sağlar. Taşer (2006: 35) konuşmayı; pratik, kültürel veya estetik nedenlerle insanlar arası bir iletişim davranışı olarak değerlendirir. Calp'a göre (2016: 103) konuşma, zihin ve kas gücünün devreye girdiği psiko-motor bir yetenek, insanlar arasında anlaşmayı sağlayan etkili bir araç, sosyal hayatta başarının yoludur. Adalı (2004:26-27) konuşmayı; zihinsel, fiziksel ve fizyolojik bir olgu olarak ifade etmektedir. Konuşmacının beyninde bildirim oluşur, beyin ses organlarına bir uyarı aktarır ve bildirim sese dönüşerek dinleyicinin kulağına gider. Thornbury (2005:2) konuşma üretiminin gerçek zamanlı ve doğrusal, plansız, şarta bağlı olarak kendiliğinden gerçekleşen bir etkinlik olarak değerlendirir. Yani bu, farklı bağlamlarda anlık olarak değişen ve gelişen, kesintiye uğrayan ve yeni bir akışa sahip olan bir süreç olarak görülebilir. Tanımlar konuşmanın fiziksel, zihinsel, sosyal, etkileşimsel ve kültürel boyutlarını ön plana çıkarmaktadır.

Ana dili ve yabancı dil öğrenme ve kullanma süreçleri, dolayısıyla da konuşma süreçleri birbirinden farklılık gösterir. Hammerly (1991: 148-149'den akt. Çolak, 2018: 10) yabancı dilde, dil öğrenim sürecinin gerçekleştiği sosyal ve kültürel çevre ile ikinci dilin edinimindeki ortamın oldukça farklı özellikler taşıdığından söz eder. İkinci dil ediniminde dilin kuralları, kullanım durumları, sosyal durumlar vb. dâhil, dilin her yönüyle iç içe bir örüntüyle ilerleyen bir sürecin aksine, yabancı dilde hedef dil deneyimleri ve etkinliklerinin sınıf ortamında ve belirli bir zamana sıkıştırılmış şekilde gerçekleştirildiğinden söz edilebilir. Dolayısıyla Türkçeyi, ana dil olarak konuşulan ülkelerin dişında öğrenen bir öğrencinin konuşma becerisini geliştirme biçimleri ile ana dili olarak konuşulan ülkelerde öğrenenlerin konuşma becerisinin gelişim düzeyi birbirinden farklılık gösterir. Bu durum kullanılan materyalin niteliğine ve öğretim sürecine de etki eder.

İletişimci Dil Öğretimi çerçevesinde yapılan çalışmaların temelini oluşturan kavramın iletişimsel edinç olduğu görülür (Fidan,2016: 133). Hymes (1972'den akt. Çetin,2017: 184), dili bilmenin uygun bağlamda, uygun kullanımlar oluşturmak olduğunu ve "iletişimsel edinç" bilgisine sahip olmanın kime, ne zaman, neyi, nasıl söyleneceğini bilmek olduğunu belirtmiştir. Canale ve Swain (1980: 29-30) iletişimsel edinci, dilbilgisel edinç, toplumdilbilimsel edinç ve stratejik edinç olmak üzere üç alt başl1kta ele alır. Canale (1983: 9) daha sonra üç boyuta söylem edincini ekler ve iletişimsel edinci dört boyutla değerlendirir. Bayraktar (2014: 116) ise bu kavramı genel olarak, ortak bir dili kullanan bir topluluk ile karşılıklı etkileşimde bulunabilmek için gerekli soyut kuralların yanı sıra, bunların toplumsal normlarla uyumlu olarak yerli-yerinde kullanılması için gerekli becerilere sahip olmak biçiminde yorumlamaktadır. Yabancı dil olarak Türkçenin öğretiminde iletişimsel edincin kazanılmasında konuşma becerisi önemli bir yer tutar. Nitekim 
konuşma, etkileşimsel bir süreçtir ve genel olarak öğrenilen dili ana dil olarak konuşanlar ile etkileşime girilmesini gerektirdiğinden iletişimsel edincin kazanılmasında önemlidir.

Türkçenin yabancı dil olarak öğretiminde konuşma becerisinin geliştirilmesine yönelik süreçler genellikle setlerde yer alan etkinlikler çerçevesinde şekillenir. Bu etkinlikler AOBM çerçevesinde iletişimsel edinci gerçekleştirmek üzere hazırlanmalıdır. Nitekim İşisağ (2008) ve Taşköprü'nün (2017) çalışmaları da konuşma becerisinde ADGD yaklaşımına göre hazırlanan sözlü iletişim becerileri dersi programının geleneksel anlayışa göre anlamlı olarak olumlu yönde sonuçlar verdiğini göstermektedir.

\section{Diller İçin Avrupa Ortak Başvuru Metni}

AOBM, öğrencilerin dil becerilerini herkesin anlayacağı ve kabul edeceği şekilde tanımlayan, dil öğrenen ve öğretenlere yol gösteren, dil öğretim programlarını şeffaf hâle getiren ve farklılıkların yol açtığ tutarsızlıktan kurtaran ve herkesin kendi ihtiyaç ve bağlamına göre uyarlayabileceği öneriler içeren bir metin (Arslangilay, 2019: 43) olarak kabul edilmektedir. İlgili metnin içerisinde ayrıca ele alınan üretimsel faaliyetler sözlü ve yazılı etkinlikleri içerir. Sözlü üretim (sözel anlatım), dil kullanıcısının bir ya da birden fazla dinleyici tarafından algılanan sözlü metin üretmesi etkinlikleridir. AOBM (Avrupa Konseyi, 2009b: 60-61) sözlü üretim konuşma etkinliklerine örnekleri aşağıdaki şekilde sıralamaktadır:

* Kamu duyuruları (bildiri, yönerge, vb.).

* Bir topluluk önünde konuşma (kamuya açık konuşmalar, üniversite dersler, vaaz, eğlence, gösteriler, spor, satış sunumları vb.).

Bu etkinliklere ilișkin bazı örnekler şöyledir:

* yazilı bir metni okuma,

* not, bir yazılı metin ya da görsel desteklerden (çizelge, resim, grafik vb.) yararlanarak konuşma,

* önceden çalış1lmış bir rolü oynama

* anında hazırlıksız konuşma

* şark1 söyleme

Belirtilen sözlü üretim etkinlikleri için tanımlayıcı ölçekler aşağıdaki şekilde belirtilmiştir:

* Genel Sözlü Üretim;

* Bağlantılı Tekil Konuşma: Deneyimleri Anlatma;

* Bağlantılı Tekil Konuşma: Gerekçelendirme (bir tartışmada olduğu gibi);

* Kamu Duyurusu;

* Bir Topluluk Önünde Konuşma;

Yukarıdaki sözlü anlatım alt küme tanımlatıcılardan da anlaşıldığı üzere bu konuşma etkinliğinde dil kullanıcısı/öğrenen sözlü bir metni üretmekte, bu metin uzakta da olabilen bir veya birden fazla dinleyici tarafindan alınmakta ve genelde yanıt vermeleri beklenmemektedir.

\section{Avrupa Dil Gelişim Dosyası}

Yabancı bir dil öğrenen bireylerin yaşam boyunca okul içinde ya da dışında gerçekleştirdikleri dil öğrenim süreci; farklı dil öğrenim yöntemleri, kültürlerarası deneyim ve dil başarı düzeylerine ait belgeler içerir. Avrupa Konseyi, bu süreç içinde oluşan kültürlerarası deneyimlerin ve belgelerin kayıt altına alınmasını sağlamak amacıyla uluslararası geçerli ve AOBM önerilerine uygun Avrupa Dil Gelişim Dosyası geliştirmiştir (Little, 2005). Avrupa Dil Gelişim Dosyası, "resmî bir değerlendirme gereksinimi olmaksızın dil kullanıcısına (dil öğrenicisine) dilsel becerilerini ve kültürlerarası deneyimini kayıt altında tutmasına olanak sağlamaktadır." (Şahin,2013: 496). Yani dil öneri düzeylerine uygun olarak belirlenen dinleme, okuma, karşılıklı konuşma, üretimsel konuşma ve yazma beceri alanlarından oluşmaktadır. 
Konuşma becerisi, AOBM'de önerildiği şekilde karşıllılı konuşma (etkileşimsel) ve sözlü anlatım (üretimsel) iki başlık altında ele alınmıştır. Kişisel Dil Başarısı bölümünde yer alan "yapabiliyorum" yeterlilik tanımları doğrultusunda dil öneri düzeyleri için sözlü anlatım ve karşılıklı konuşma yeterlilik tanımları verilmiştir. Bu tanımlamalar dil öğrenicisinin hedef dili etkin bir biçimde kullanabilmesi bakımından önemlidir.

İlgili alanyazın incelendiğinde ders kitaplarındaki konuşma etkinliklerinin incelendiği çeşitli çalışmalar mevcuttur (Yavuz Kırık, 2015; Biçer ve Kılıç, 2017; Çolak, 2018). Yavuz ve Kırık (2015) ders kitaplarındaki konuşma etkinliklerinin etkileşimsellik düzeyini; Kurudayığlu (2019) konuşma türleri bakımından; Biçer ve Kılıç (2017) içerik, biçimsel özellikler, öğrenci seviyesine uygunluk, temel dil becerilerinin dağılımı ve etkinliklerin uygulanması bakımından; Çolak (2018) B1 düzeyindeki etkinlikleri AOBM konuşma yeterlilikleri bağlamında; Hasırcı (2019) etkinlikleri ünite içindeki dağılım, soru türleri, doğruluk ve akıcılık, etkileşim, gerçek yaşama yer verme, grup etkinliği oluşturma diğer becerilerle ve konuşma etkinlikleriyle ilişkilendirilme gibi açılardan değerlendirmişlerdir.

Alanyazında anahtar kelimeler ile yapılan taramada, yaygın olarak kullanılan dört setin karşı1ıklı olarak yeterlilik tanımları bağlamında değerlendirildiği çalışmaya rastlanılamamıştır. Bu bakımdan araştırma, konuşma becerisi açısından eksik kalan yeterlilik düzeylerini ve geliştirilmesi gereken alanları ortaya koyma bakımdan önemlidir. Bu bakımdan araştırmada temel düzey A1 seviyesinde Türkçenin yabancı dil olarak öğretiminde kullanılan setlerde yer alan konuşma becerisi etkinliklerinin Avrupa Dil Gelişim Dosyası yeterlilik tanımlarına dağılım durumunu belirlemek amaçlanmıştır. Bu doğrultuda aşağıdaki sorulara cevap aranmıştır.

1. A1 seviyesinde Türkçenin yabancı dil olarak öğretiminde kullanılan ders kitaplarında yer alan konuşma becerisi etkinliklerinin Avrupa Dil Gelişim Dosyası bağlamındaki konuşma becerisinin boyutlarına (karşı1ıklı konuşma ve sözlü anlatım) göre dağılımı nasıldır?

2. A1 seviyesinde Türkçenin yabancı dil olarak öğretiminde kullanılan ders kitaplarında yer alan konuşma becerisi etkinliklerinin Avrupa Dil Gelişim Dosyası yeterlilik tanımlarına dağılımı nasıldır?

\section{Yöntem}

\section{Araştırmanın Modeli}

$\mathrm{Bu}$ çalışmada nitel araştırma yöntemlerinden durum çalışması kullanılmıştır. Durum çalışması, güncel bir olay veya durumu derinlemesine incelemeyi amaçlayan; çoklu araştırma araçlarının kullanıldığı ve buna bağlı olarak durumun ya da duruma bağlı etkenlerin temalaştırılabildiği bir araştırma yaklaşımıdır (Yin, 2014; Creswell, 2016) Araştırmada, A1 seviyesine ait İstanbul Yabancılar İçin Türkçe ders ve çalışma kitabı, Yedi İklim Türkçe ders ve çalışma kitabı, Yeni Hitit Türkçe ders kitabı ve Gazi Yabancılar İçin Türkçe ders ve çalışma kitaplarındaki konuşma becerisine yönelik durumlar tespit edilmiştir. Araştırmanın deseni durum çalışmalarından iç içe geçmiş tek durum desenidir. Araştırma Türkçenin yabancı dil olarak öğretimine yönelik hazırlanmış ders kitaplarında yer alan konuşma etkinliklerinde birden fazla türü ele aldığı ve bunlara ilişkin kategorilendirme tek bir yapıyı açıklamak için kullanıldığından iç içe geçmiş tek durum deseni özelliği göstermektedir.

\section{Araştırmanın İnceleme Nesneleri}

Araştırmanın inceleme nesnelerini İstanbul Yabancılar İçin Türkçe ders ve çalışma kitabı (A1) Gazi Yabancılar İçin Türkçe ders ve çalışma kitabı (A1), Yeni Hitit Yabancılar İçin Türkçe ders ve çalışma kitabı (A1/A2), Yedi İklim Türkçe ders ve çalışma kitabı (A1) oluşturmaktadır. Araştırmanın inceleme nesnelerini belirlemede Türkçenin yabancı dil olarak öğretiminde en yaygın kullanılan setler olmaları esas alınmıştır. 


\section{Verilerin Toplanması ve Analizi}

Araştırma kapsamında doküman incelemesinden yararlanılmıştır. Belgesel tarama olarak da adlandırılan doküman incelemesinde temel amaç araştırılması hedeflenen olgu veya olgular hakkında bilgi içeren materyallerin analiz edilmesidir. (Yıldırım ve Şimşek, 2013). Belgesel taramanın iki ayrı amaçla yapılabileceğini belirten Karasar (2013) bu amaçları, genel tarama ve içerik çözümlemesi olarak tanımlar. Genel tarama "alanyazın" veya "edebiyat" taraması olarak bilinen bir yöntemdir. İçerik analizi ise belli bir metnin, kitabın, belgenin belli özelliklerini sayısallaştırarak belirleme amacı ile yapılan bir taramadır. Araştırma kapsamında, AOBM ve ADGD incelenmiş, çalışma konusu olan dört dil becerisi ile ilgili önerilen alanlar, konuşma becerisi ile ilgili tanım ve yeterlilik ölçütleri saptanmıştır. Bu doğrultuda Türkçe öğretim merkezlerinde en yaygın kullanılan dört set araştırma kapsamına alınmış ve bu setlerde yer alan konuşma becerisi etkinlikleri konuşma becerisinin boyutları, AOBM ve ADGD yeterlilik ölçütlerine göre sınıflandırılmıştır. İlgili sınıflandırma esnasında alan uzmanlarından görüş alınmıştır. Araştırmacı ve uzman görüşleri doğrultusunda Gazi Yabancılar İçin Türkçe setinden 10 etkinlik ve Yeni Hitit setinden 1 etkinlik ilgili yeterlilikler ile örtüşmediği için araştırma kapsamına alınmamıştır.

\section{Bulgular}

$\mathrm{Bu}$ bölümde temel düzey A1 düzey, ders kitaplarında yer alan konuşma becerisi etkinliklerinin konuşma becerisinin boyutlarına (karşılıklı konuşma ve sözlü anlatım) ve ADGD yeterlilik ölçütlerine göre taranması sonucu elde edilen bulgular yer almaktadır.

\section{Alt Probleme İlişkin Bulgular:}

Grafik 1: A1 Seviyesindeki Yabanc1lara Türkçe Öğretimi Ders Kitaplarında Yer Alan Konuşma Becerisi Etkinliklerinin Avrupa Dil Gelişim Dosyası Bağlamındaki Konuşma Becerisinin Boyutuna (Karşılıklı Konuşma ve Sözlü Anlatım) Göre Dağılımı

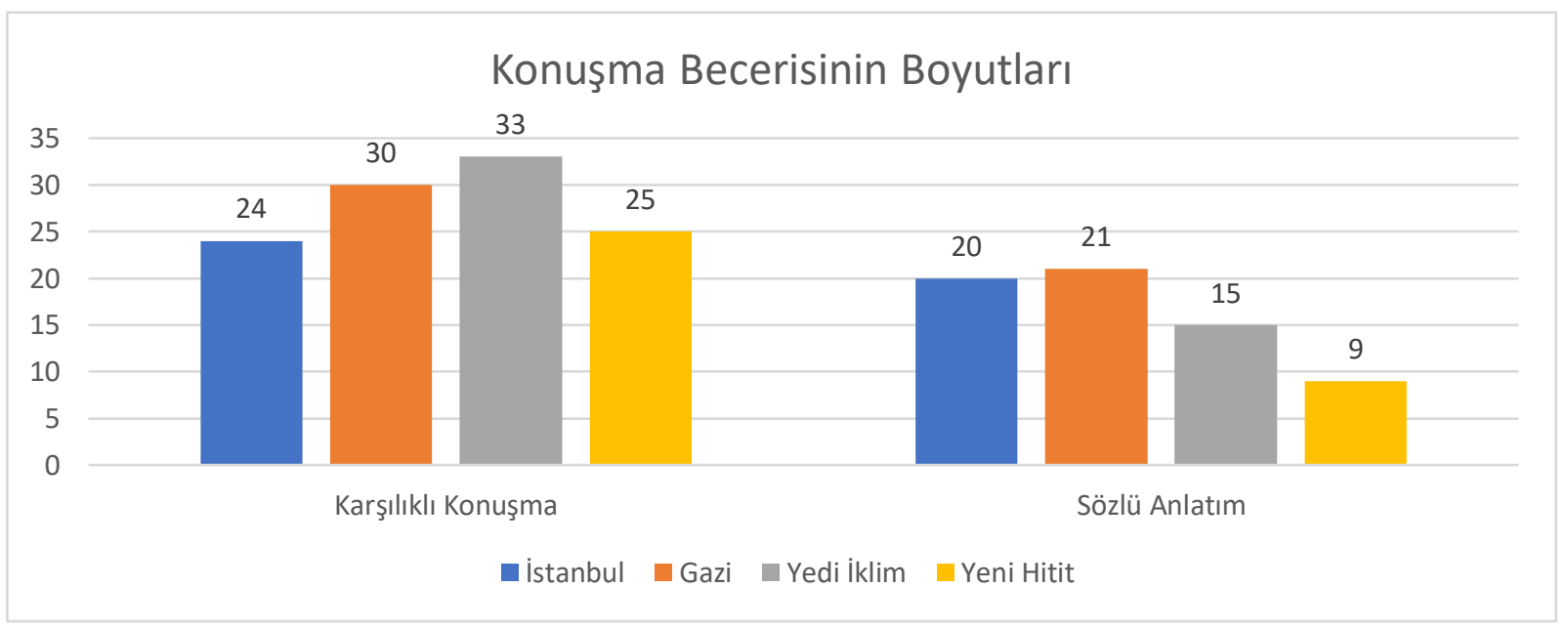

Grafik 1'e göre konuşma becerisinin karşıllklı konuşma boyutunda en fazla etkinlik Yedi İklim (33) setinde bulunurken bunu sirasiyla Gazi (30), Yeni Hitit (25) ve İstanbul (24) setleri izlemektedir. Karşılıklı konuşma bakımından etkinlik sayılarının birbirlerine benzer sonuçlar gösterdiği ifade edilebilir. Sözlü anlatım boyutunda ise en fazla etkinlik sırasıyla Gazi (21), İstanbul (20), Yedi İklim (15) ve Yeni Hitit (9) setlerindedir. Özellikle Yeni Hitit setindeki sözlü anlatım etkinliklerinin sayısal bakımdan azlığı dikkat çekicidir. Bütün ders kitapları dikkate alındığında karşılıklı konuşmaya ilişkin toplam etkinlik sayısı 112 iken sözlü anlatım 65 etkinlik ile 
sınırlı kalmıştır. Ayrıca ders kitaplarının tamamında etkinlik sayıları bakımından karşılıklı konuşmanın lehine belirgin bir fark vardır. Bu farkın en belirgin şekilde görüldüğü setler Yeni Hitit ve Yedi İklim'dir.

\section{Alt Probleme İlişkin Bulgular:}

Tablo 1: Türkçe Setlerine İlişkin Etkinlik\Yeterlik Tablosu

\begin{tabular}{|c|c|c|c|c|c|c|c|c|c|c|c|c|c|c|c|c|}
\hline \multirow[b]{2}{*}{ SETLER } & \multicolumn{12}{|c|}{ KARŞILIKLI KONUŞMA } & \multicolumn{4}{|c|}{ SÖZLÜ ANLATIM } \\
\hline & $\begin{array}{l}\overrightarrow{1} \\
\frac{1}{2}\end{array}$ & $\frac{N}{\mathbb{Z}}$ & $\frac{n}{i}$ & $\begin{array}{l}\stackrel{+}{ \pm} \\
\underset{\mathbb{V}}{\mathbb{V}}\end{array}$ & $\begin{array}{r}i \\
\mathbb{1} \\
\mathbb{1}\end{array}$ & 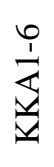 & $\frac{1}{\sqrt{1}}$ & $\begin{array}{l}\infty \\
\frac{1}{\mathbb{V}} \\
\mathbb{1}\end{array}$ & $\frac{a}{\sqrt{1}}$ & $\begin{array}{l}\stackrel{0}{1} \\
\frac{1}{4} \\
\frac{1}{1}\end{array}$ & $\begin{array}{l}\underset{1}{J} \\
\frac{1}{\Delta}\end{array}$ & 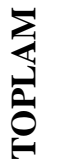 & $\underset{\sim}{\stackrel{1}{4}}$ & 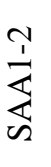 & 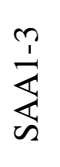 & $\sum_{\substack{0 \\
0}}$ \\
\hline İstanbul & 4 & 3 & 3 & - & 2 & - & 2 & 8 & 1 & - & 1 & 24 & 5 & 6 & 9 & 20 \\
\hline Gazi & 2 & 3 & 3 & 5 & 5 & 6 & 3 & 1 & 1 & - & 1 & 30 & 4 & 8 & 9 & 21 \\
\hline $\begin{array}{l}\text { Yedi } \\
\text { İklim }\end{array}$ & 9 & 5 & 3 & 2 & - & 2 & 4 & 4 & 2 & - & 2 & 33 & 3 & 4 & 8 & 15 \\
\hline $\begin{array}{l}\text { Yeni } \\
\text { Hitit }\end{array}$ & 4 & 4 & - & 2 & 5 & 1 & 5 & 2 & 1 & - & 1 & 25 & 2 & 3 & 4 & 9 \\
\hline Toplam & $\begin{array}{l}1 \\
9\end{array}$ & 15 & 9 & 9 & 12 & 9 & 14 & 15 & 5 & - & 5 & 112 & 14 & 21 & 30 & 65 \\
\hline
\end{tabular}

Tabloda incelenen öğretim setlerinin her bir karş1lıklı konuşma (KK) ve sözlü anlatım (SA) yeterliliğine dair oluşturdukları etkinlik sayılarına yer verilmiştir. Öğretim setlerinin ilgili yeterliliklere yer verme durumlarına dair verileri aşağıda yorumlanmıştır:

\section{İstanbul Setine İlişskin Bulgular}

Etkinliklerin ADGD yeterlilik ölçütlerine göre dağılımında belli ölçütlere ait etkinliklere ağırlıklı olarak yer verildiğ ve dengeli bir dağılım olmadığı gözlenmiştir. Ayrıca etkinliği bulunamayan 3 adet ADGD yeterlilik ölçütü saptanmış olup ölçütlerin tanımları şöyledir: yapabilirim.

KKA1-4: Konuşmamı destekleyen jest ve mimiklerin yardımıyla küçük alışverişler

KKA1-6: Herhangi bir şeyi isteyebilir ve istenilen bir şeyi verebilirim.

KKA1-10: Özür dileyebilir ve özürleri kabul edebilirim.

Etkinliği saptanamayan 3 yeterlilik ölçütü de karş1lıklı konuşma becerisi ile ilgilidir. 8 etkinlik ile en çok yer verilen karşılıklı konuşma yeterlilik ölçütü ise KKA1-8 olup, tanımlaması şöyledir:

KKA1-8: "Gelecek Hafta", "Geçen Cuma", "Kasım'da” ve "Saat 3'te" gibi zaman ifadelerini kullanabilirim.

Sözlü anlatım becerisi etkinliklerinde 9 etkinlik ile en çok yer verilen yeterlilik ölçütü SAA1-3 olup, tanımlaması şöyledir:

SAA1-3: Basit bir dille günlük hayatta neler yaptı̆̆ıma ilişkin bilgi verebilirim. 


\section{Örnekler:}

KKA-1-2( İstanbul Yabancılar İçin Türkçe ders kitabı, 2012: 11)

\section{YAZMA}

8 Aşağıdaki cümleleri kullanalım ve sınıftaki arkadaşlarımızla bir diyalog yazalım.

- Senin adın ne?

- Nasılsın?

- Nerelisin?

- Memnun oldum.

\section{KONUȘMA}

9 Kitabı kapatalım. Aynı soruları arkadaşlarımıza soralım.
SAA1-2 (İstanbul Yabancılar İçin Türkçe ders kitab1, 2012: 25)

\section{KONUŞMA}

13 Sizin odanızda neler var? Anlatalım.
SAB1-3 (İstanbul Yabancilar İçin Türkçe ders kitab1, 2012: 47)

\section{KONUŞMA}

(10) Planlarımız hakkında konuşalım.

- Dersten sonra ne yapmak istiyorsun?

- Neden Türkçe öğrenmek istiyorsun?

- 10 sene sonra nerede olmak ve ne yapmak istiyor-

sun?

\section{Gazi Setine İlişkin Bulgular}

Etkinliklerin ADGD yeterlilik ölçütlerine göre dağılımına bakıldığında dengeli bir dağılım görülmekte olup etkinliği bulunmayan 1 adet karşılıklı konuşma yeterlilik ölçütünün tanımı şöyledir:

KKA1-10: Özür dileyebilir ve özürleri kabul edebilirim.

6 etkinlik ile en çok yer verilen karşı1ıklı konuşma yeterlilik ölçütü ise KKA1-6 olup tanımlaması şöyledir:

KKA1-6: Herhangi bir şey isteyebilir ve istenilen bir şeyi verebilirim.

Sözlü anlatım becerisi etkinliklerinde 10 etkinlik ile en çok yer verilen yeterlilik ölçütü SAA1-3 olup tanımlaması şöyledir:

SAA1-3: Basit bir dille günlük hayatta neler yaptı̆̆ıma ilişskin bilgi verebilirim. 


\section{Örnekler:}

KKA2-5 (Gazi Yabancılar İçin Türkçe, 2013: 28) KKA2-4 (Gazi Yabancılar İçin Türkçe, 2013: 34)
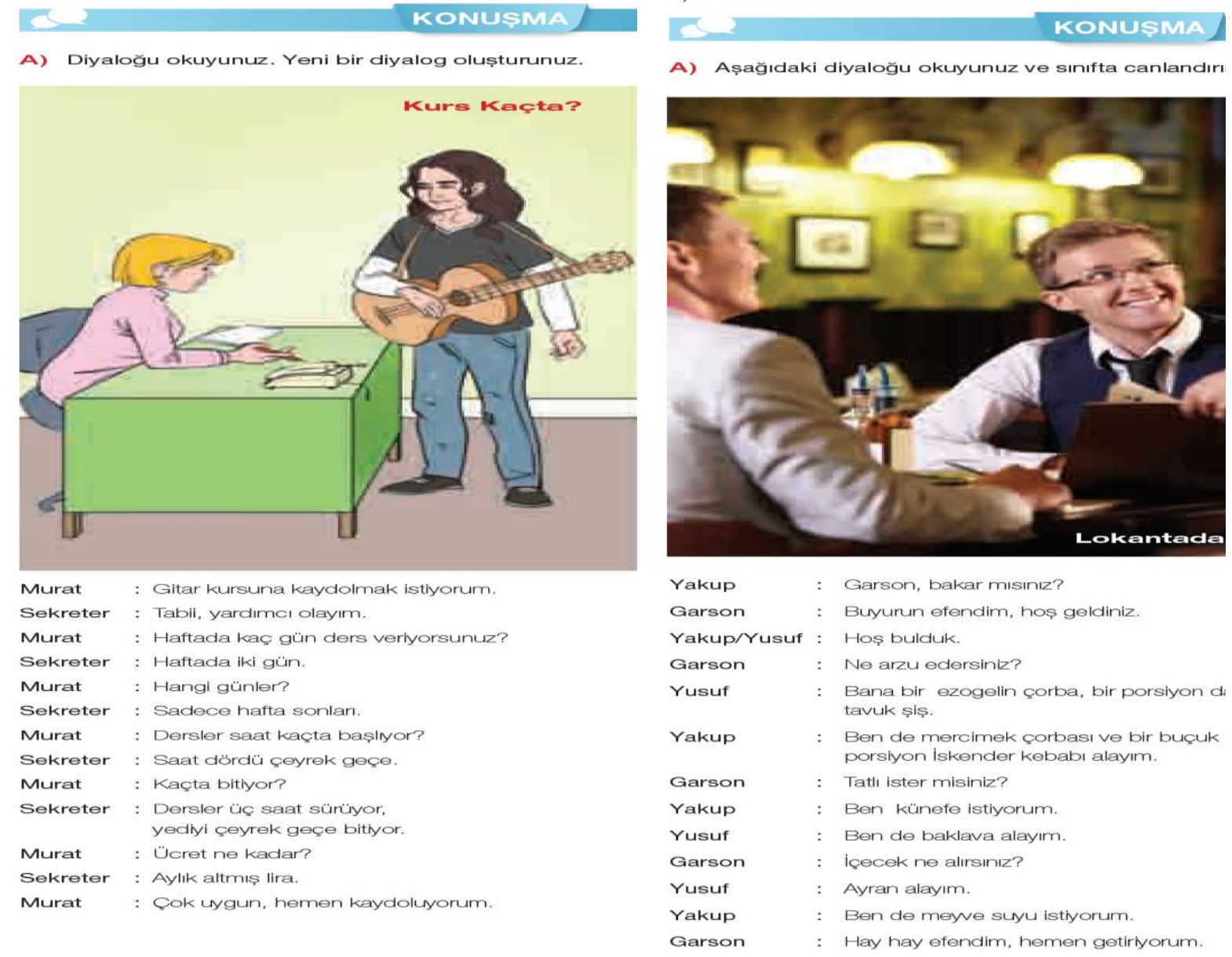

\section{Yedi İklim Setine İlişskin Bulgular}

Etkinliklerin ADGD yeterlilik ölçütlerine göre dağılımında belli ölçütlere ait etkinliklere ağırlıklı olarak yer verildiği ve dengeli bir dağılımın olmadığı gözlenmektedir. Ayrıca etkinliği bulunamayan 2 adet ADGD yeterlilik ölçütü saptanmış olup ölçütlerin tanımları şöyledir:

KKA1-5: Rakam, miktar, fiyat ve saat ile ilgili ifadeleri kullanabilirim.

KKA1-10: Özür dileyebilir ve özürleri kabul edebilirim.

Etkinliği saptanamayan 2 yeterlilik ölçütü de karşllıklı konuşma becerisi ile ilgilidir. 9 etkinlik ile en çok yer verilen karşılıklı konuşma yeterlilik ölçütü ise KKA1-1 olup, tanımlaması şöyledir:

KKA1-1: Tanışma, selamlaşma ve vedalaşmaya ilişkin kalıp ifadeleri kullanabilirim.

Sözlü anlatım becerisi etkinliklerinde 8 etkinlik ile en çok yer verilen yeterlilik ölçütü SAA1-3 olup, tanımlaması şöyledir:

SAA1-3: Basit bir dille günlük hayatta neler yaptı̆̆ıma ilişkin bilgi verebilirim. 
Örnekler:

KKA1-1 (Yedi İklim Türkçe, 2015: 12)

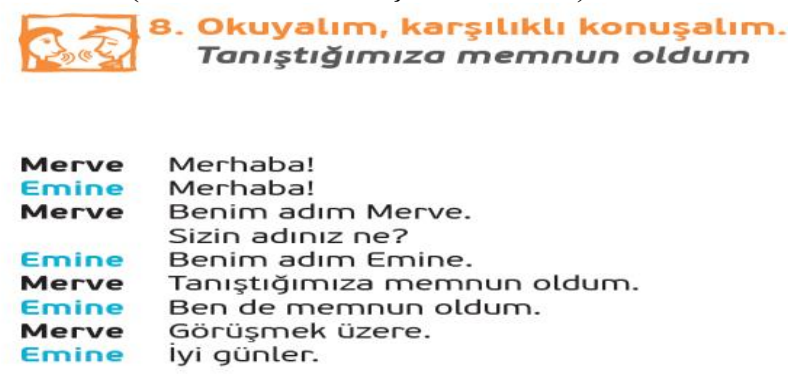

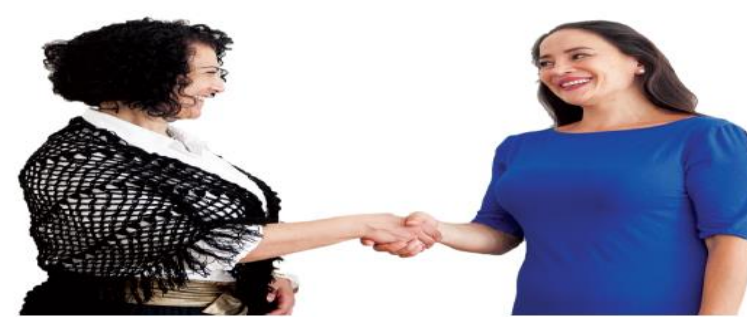

SAB1-3 (Yedi İklim Türkçe, 2015: 63)
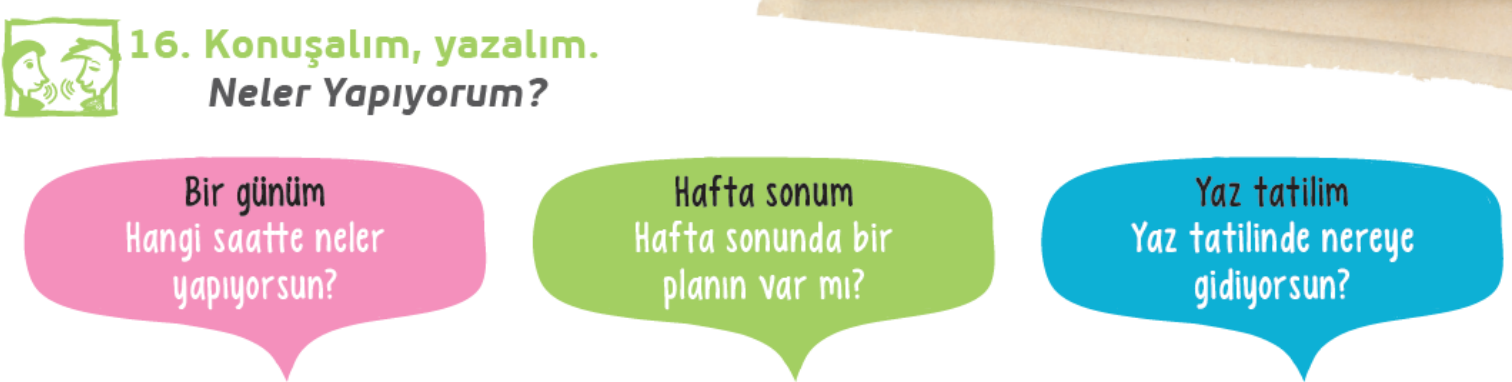

\section{Yeni Hitit Setine İlişkin Bulgular}

Etkinliklerin ADGD yeterlilik ölçütlerine göre dağılımında belli ölçütlere ait etkinliklere ağırlıklı olarak yer verildiği ve dengeli bir dağılım olmadı ğı gözlenmiştir. Etkinliği bulunamayan 2 adet ADGD yeterlilik ölçütü saptanmış olup ölçütlerin tanımları şöyledir:

KKA1-3: Konuştuğum kişinin söylenenleri yavaş bir şekilde tekrar edip söylemek istediğimi ifade etmeme yardımcı olması durumunda kendimi basit bir şekilde ifade edebilirim.

KKA1-10: Özür dileyebilir ve özürleri kabul edebilirim.

Etkinliği saptanamayan 2 yeterlilik ölçütü de karş1lıklı konuşma becerisi ile ilgilidir. Beşer etkinlik ile en çok yer verilen karş11ıkl konuşma yeterlilik ölçütleri ise KKA1-5 ve KKA1-7 olup tanımlamaları şöyledir:

KKA1-5: Rakam, miktar, fiyat ve saat ile ilgili ifadeleri kullanabilirim.

KKA1-7: Kişilere nerede yaşadıkları, kimleri tanıdıkları ve sahip oldukları şeylere ilişkin sorular sorabilir ve bu tür sorulart yavaş ve açı sorulduğunda yanıtlayabilirim.

Sözlü anlatım becerisi etkinliklerinde 4 etkinlik ile en çok yer verilen yeterlilik ölçütü SAA1-3 olup, tanımlaması şöyledir:

SAA1-3: Basit bir dille günlük hayatta neler yaptığıma ilişkin bilgi verebilirim. 


Örnekler:
\begin{tabular}{|l|l|l|}
\hline Yeni Hitit, 2016: 21 & Yeni Hitit, 2016: 87 \\
\hline $\mathbf{5}$ Soralım, anlatalım & $\mathbf{2 3}$ Anlatalım \\
\hline Neler Yapıyorsun? & On Yıllık Planlarım \\
Bir günün nasıl geçiyor? & Aile \\
Sabahları ne yapıyorsun? & \\
Oğlenleri ne yapıyorsun? & \\
Hafta sonlanı ne yapıyorsun? & \\
\hline
\end{tabular}

Araştırma kapsamında elde edilen bulgular mukayeseli olarak incelendiğinde yeterliliklerin setlere dengeli bir biçimde dağılmadığı ve bunun yanı sıra öncelik-sonralık gibi bir denge de gözetilmediği görülmektedir. Her kitapta aynı yeterliliğe yer verme bakımından büyük farklılıklar görülmektedir. Ayrıca KKA1-10 hiçbir sette yer almamaktadır. KKA1-9 ise çok düşük oranda yer almaktadır.

\section{Tartışma ve Sonuç}

Araştırmada elde edilen bulgulardan hareketle ders kitaplarında konuşma becerisinin boyutları (karşılıklı konuşma ve sözlü anlatım) bakımından dengeli bir dağılımın olmadığ1 görülmektedir. A1 düzeyinin dili öğrenenler için bir keşif düzeyi olması, bu düzeyde dilin temelde kişisel amaçlar için kullanılması, öğrenenin hedef dilde basit karşılıklı etkileşime girdiği en temel düzey olması bakımından tüm ders kitaplarında karşılıklı konuşma etkinliklerinin oranının sözlü anlatım etkinliklerinden daha yüksek olduğu düşünülmektedir. Nitekim Çolak (2018) B1 düzeyinde yaptığ 1 araştırmada sözlü anlatım etkinliklerinin karşılıklı konuşma etkinliklerine oranla çok daha yüksek olduğunu ifade etmektedir. Bu bakımdan düzeyler arasında karşlıklı konuşmadan sözlü anlatıma yönelik bir artış olduğu düşünülebilir. Ayrıca ADGD'de yer alan yeterlilikler de benzer bir dağılım göstermektedir. ADGD'de karşılıklı konuşma boyutunda 11 yeterlilik yer alırken sözlü anlatım boyutunda 3 yeterlilik yer almaktadır. Etkinliklerin konuşmanın boyutlarına göre sayısal dağılımları bakımından İstanbul ve Gazi setinin oranları birbirine daha yakınken özellikle Yedi İklim ve Yeni Hitit setinde karşılıklı konuşmanın lehine ciddi bir fark mevcuttur.

Ders kitaplarında yer alan etkinliklerin Avrupa Dil Gelişim Dosyası yeterlilik ölçütlerine dağılım verilerinde tüm ders kitaplarında en az bir yeterliliğge yer verilmediği belirlenmiştir. KKA1-10 (Özür dileyebilir ve özürleri kabul edebilirim.) ise hiçbir sette yer almamaktadır. Toplum hayatı içerisinde bireylerin çok basit durumlarda bile özür dileme ihtiyacının var olacağg göz önüne alındığında bu durum setlerde bir eksiklik olarak düşünülmektedir. Bununla birlikte İstanbul setinde konuşma becerisine ait 3 yeterlik tanımına ilişkin etkinlik hiç yer almazken Yedi İklim ve Yeni Hitit setinde bu sayı 2, Gazi setinde ise 1'dir. Bu durum kitap hazırlayıcılarının ADGD'yi göz ard1 ettiklerini göstermektedir.

Ayrıca ders kitaplarında yer alan bazı etkinliklerin ADGD yeterlilik tanımlarına uymadığı saptanmıştır. A1 Gazi Yabancılar için Türkçe ders kitabında yer alan 61 adet konuşma becerisi etkinliğinin 10 adedi, Yeni Hitit ders kitabında 35 etkinliğin 1 adedi ADGD yeterlilik tanımlarıyla uyuşmamaktadır. $\mathrm{Bu}$ durum ders kitabı yazarlarının ders kitabı yazım esnasında çerçeve metni yeterince dikkate almadığı şeklinde yorumlanabilir. Pek çok ülkede yabancı dil eğitiminin AOBM'ye göre yapıldığı düşünüldüğünde yeterlilik düzeyindeki bu tür farklılıklar dil sınavları ve sertifikalandırma yönünden karışıklıklara sebep olabilecektir. $\mathrm{Bu}$ bakımdan ders kitapları hazırlanırken ortak öneri düzeyleri ve yeterlilikler dikkate alınmalı, sözlü anlatım ve karş1lıklı konuşmaya ilişkin etkinlikler hedeflenen niteliği en iyi şekilde yansıtacak şekilde tasarlanmalıdır. 
Kitaplarda yer konuşma etkinlikleri seviyere uygun şekilde AOBM'nin temel yaklaşımı olan eylem odaklılığa uygun olarak üretilmelidir. Son yıllarda AOBM'den hareketle dil öğretiminde öğrencilerin içinde yer aldıkları dilsel görevlerle dili kazanmaları hedeflendiğinden, hazırlanan konuşma etkinliklerinin öğrencileri sözlü dil görevlerine yönlendirmeleri uygun olacaktır.

\section{Kaynakça}

Adal1, O. (2004). Anlamak ve anlatmak. Pan Yayınları.

Aksan, D. (2007). Her yönüyle dil ana çizgileriyle dilbilim (4. bs.). Türk Dil Kurumu Yayınları.

Arslangilay, A.S. (2019). Diller için Avrupa ortak öneriler çerçevesi ve tamamlayıcı kitap. Ü. Şen (Ed.), Yabancı dil olarak Türkçe öğretimi içinde (s.42-64). Pegem Yayınevi.

Avrupa konseyi (2009a). Common European Framework of References for language: Learning, Teaching, Assestment. çev. MEB Çeviri Komisyonu. T.C. Millî Eğitim Bakanlığı Talim ve Terbiye Kurulu Başkanlığı Yayınları.

Avrupa konseyi. (2009b). Common European framework of references for language: Learning, teaching, assestment (çev. telc $\mathrm{GmbH}$ ). telc $\mathrm{GmbH}$.

Bayraktar, H. (2014). Yabancı dilde iletişimsel yeterlilik kavramının tarihçesi ve dil ögretimine yansımaları. A. Şahin (Ed.), Yabancı dil olarak Türkçe öğretimi içinde (s.113-130). Pegem Yayınevi.

Biçer, N. ve Kılıç, B. S. (2017). Suriyeli öğrencilere Türkçe öğretmek için kullanılan ders kitaplarının öğretmen görüşleri doğrultusunda değerlendirilmesi. Ana Dili Ĕgitimi Dergisi, 5(4), 649-663. Calp, M. (2016). Özel eğitim alanı olarak Türkçe öğretimi. Nobel Yayınevi.

Canale, M. ve Swain, M. (1980). "Theoretical bases of communicative approaches to second language teaching and testing". Applied Linguistics, 1: 1-47.

Canale, M. (1983). "From communicative competence to communicative language pedagogy". J.C. Richards \& R.W. Schmidt, (Ed). Language and communication içinde (s.2-27). Longman.

Creswell, J. W. (2016). Nitel araştırma yöntemleri: Beş yaklaşıma göre nitel araştırma ve araştırma deseni (M. Bütün ve S. B. Demir, Çev.; 3. bs). Siyasal Kitabevi.

Çetin, B. (2017). "İletişimsel edinç ve yabancı dil olarak Türkçede dilbilgisi öğretimi, Turkish Studies -International Periodical for the Languages, Literature and History of Turkish or Turkic-, (12)6: 179-196.

Çolak, M. (2018). Yabanclikinci dil olarak Türkçe konuşma becerisinin Yedi İklim B1 düzeyi ders materyalleri üzerinden değerlendirilmesi. Yayımlanmamış yüksek lisans tezi. Hacettepe Üniversitesi Türkiyat Araştırmaları Enstitüsü.

Demirel, Ö. (1999). Yabancı dil ögretimi. MEB Yayınları.

Fidan, Ö. (2016). Türkçenin yabanclikinci dil olarak öğretimi: Konuşma. F. Yıldırım ve B. Tüfekçioğlu (Ed.), Yabanc1 dil olarak Türkçe öğretimi içinde (s.129-155). Pegem Yayınevi.

Hasırcı, S. (2019). Yabancılara Türkçe öğretimine yönelik ders kitaplarının konuşma becerisi açısından karşılaştırılması. Uluslararası Türkçe Edebiyat Kültür Eğitim (TEKE) Dergisi, 8(2), 1068-1098.

İşeri, K. (2007). Altıncı sınıf Türkçe ders kitabının ilköğretim Türkçe programının amaçlarına uygunluğunun değerlendirilmesi. Dil Dergisi, (136), 58-74. 
İşisağ, K. U. (2008). Sözlü iletişim becerilerinin gelişiminde diller için Avrupa ortak başvuru metni uygulamalarının başarıya, tutuma ve kalıcılığa etkisi. (Yayımlanmamış yüksek lisans tezi). Ankara Üniversitesi.

Günay, D. (2016). Öğrenen özerkliği, İngilizce öğretimine yansımaları ve HAYEF örneğinde öğretmen adaylarının değişen öğretmen rolleri algısı. HAYEF Dergisi, (13)3: 17-30.

Karakoç Öztürk, B. (2016). Yabancı dil olarak Türkçe öğretiminde materyal tasarımı- süreç ve etkinlikler-. F. Yıldırım ve B. Tüfekçioğlu (Ed.), Yabancı dil olarak Türkçe ögretimi: Kuramlar -yöntemler- beceriler- uygulamalar içinde . Pegem Yayınevi.

Karasar, N. (2013). Bilimsel araştırma yöntemleri (25.bs.). Nobel Yayınevi.

Kurudayığlu, M. (2019). Yabancı dil olarak Türkçe ders kitaplarındaki konuşma etkinliklerinin konuşma türleri açısından İncelenmesi. Ana Dili Eğitimi Dergisi, 7(3), 736-750.

Kurudayığlu, M. ve Sapmaz, S. (2016). Yabancı dil olarak Türkçe konuşma öğretimine dair öğretmen bilişleri. Zeitschrift für die Welt der Türken / Journal of World of Turks, 8(3), 85102.

Little, D. ve Radka P. (2001) The European language portfolio: A guide for teachers. Avrupa Konseyi.

Little, David. 2005. The common European framework and the European language portfolio: involving learners and their judgments in the assessment process. Language Testing. 22 (3): 321-336.

Mirici, İ.H. ve Demire, Ö. (2002). Yabanc1 dil eğitiminde öğrenen özerkliği. Milli Eğitim Dergisi. s.155-156: 76-88.

Özbay, M. (2003). Öğretmen görüşlerine göre ilköğretim okullarında Türkçe ögrretimi. Gölge Ofset Matbaacilik.

Özdemir, E. (1992). Güzel ve etkili konuşma. Remzi Kitabevi.

Şahin, A. (2013). Dil öğretiminde uluslararası ölçütler. M. Durmuş ve A. Okur (Ed.), Yabancılara Türkçe ögretimi: El kitabı içinde. Grafiker Yayınları.

Taşer, S. (2006). Konuşma Eğitimi. Papirüs Yayınları.

Taşköprü, G. (2015). Yabancı dil olarak Türkçe sınıflarında konuşma becerisini geliştirmeye yönelik materyal hazırlama. (Yayımlanmamış yüksek lisans tezi). Dokuz Eylül Üniversitesi, İzmir.

Tüm, G. (2014). Çok Uluslu Sınıflarda Yabancı Dil Türkçe Öğretiminde Karşılaşılan Sesletim Sorunları. Hacettepe Üniversitesi Ĕ̈itim Fakültesi Dergisi, 29(2), 255-266.

Yavuz Kırık, M. (2015). Interaction level of speaking activities in a coursebook series of teaching Turkish as a foreign language. Hasan Ali Yücel Ë̆itim Fakültesi Dergisi, 12- 2(24), 133145 .

Yıldırım, A., \& Şimşek, H. (2013). Sosyal bilimlerde nitel araştırma yöntemleri (9. bs). Seçkin Yayınevi.

Yin, Y.K (2014). Case study research: Design and methods (5th editions). Thousand Oaks.: Sage. 